\title{
Cost and Efficacy of Water Disinfection Practices: Evidence from Canada
}

\author{
ARIAN KHALEGHI MOGHADAM \\ Bloomsburg University of Pennsylvania \\ MOHAMMED DORE \\ Brock University ${ }^{*}$
}

\begin{abstract}
This study investigates the cost and efficacy of water disinfection practices using data from Canadian Municipal Water and Wastewater Survey. Since only a small number of municipalities use UV or ozone, this study investigates whether the dominant use of chlorine-based disinfectants is due to their efficacy in preventing microbiological problems or because UV or ozone imposes an unacceptably high financial burden on municipalities. The results suggest that the use of UV or ozone can lead to a lower likelihood of having microbiological problems and that the dominant use of chlorinebased disinfection cannot be based on cost comparisons alone.
\end{abstract}

Keywords: impact analysis, water disinfection.

JEL Classifications: L95, Q25, Q53.

\section{Introduction}

Despite the good quality and uninterrupted flow of treated water entering most Canadian homes, concerns about the supply of drinking water and its safety have sharply intensified in recent years. This is partially due to the long-standing concerns about the supply of safe drinking water, but it is also due to the severe outbreaks of waterborne diseases both in Canada and around the world. ${ }^{1}$ Disinfection of drinking water is a vital part of any drinking

\footnotetext{
* This research is partly funded by a research grant from the Social Sciences and Humanities Research Council of Canada. However, the authors alone are responsible for its contents. In addition, we would like to thank Felice Martinello and Burc Kayahan for comments.

(C) 2012 Arian Khaleghi Moghadam and Mohammed Dore. Licensed under the Creative Commons Attribution - Noncommercial 3.0 Licence (http://creativecommons.org/licenses/bync/3.०/. Available at http://rofea.org.

${ }^{1}$ For example, toxoplasmosis outbreaks in Victoria, British Columbia (1995) and Santa Isabel do Ivai, Brazil (2002); E. coli outbreaks in Cabool, Missouri (1989) and Walkerton, Ontario (2000); cryptosporidium outbreaks in Milwaukee, Wisconsin (1993), Kitchener and Waterloo, Ontario (1993), Cranbrook, British Columbia (1996), Kelowna, British Columbia (1996), North Battleford, Saskatchewan (2001), the greater Belfast area, Northern Ireland (2000 to 2001), Gwynedd and Anglesey areas, North-West Wales (2005); Giardiasis outbreaks in Bradford, Pennsylvania (1979), Pittsfield, Massachusetts (1985) and Pinticton, British Columbia (1986).
} 
water system. This is to ensure that drinking water carries no microorganisms that can put human health at risk.

In Canada, like in many other countries, the use of chlorine-based disinfectants is the most common disinfection practice in the drinking water systems. While the production and use of free chlorine is relatively cheap and easy, the formation of chlorination disinfection byproducts (DBPs) associated with the use of chlorine-based disinfectants has raised many concerns in recent years. For example, some epidemiological studies report higher risks of chronic myeloid leukemia (Kasim, et al., 2006), bladder cancer (Chevrier, et al., 2004, Villanueva, et al., 2003), and colon cancers (King, et al., 2000) associated with increasing years of exposure to different DBPs. This has led many European countries to take steps to limit the use of chlorine-based disinfectants whenever possible and replace them with other alternative methods such as the use of UV or ozone. In contrast, only a small number of Canadian municipalities (less than $18 \%$ of the municipalities in the survey of municipal water and wastewater) have opted out of using chlorine-based disinfectants. Therefore, it is important to investigate whether the dominant use of chlorine-based disinfectants is due to their efficacy in preventing microbiological problems or because the use of UV or ozone imposes an unacceptably high financial burden on municipalities. The purpose of this study is to answer these questions by developing an impact analysis for the most common water disinfection practices. These are chlorine, chloramines, chlorine dioxide, UV and ozone. The first objective is to quantify by how much (and if) the use of a disinfection practice can lower the probability of having microbiological problems in a drinking water system. The second objective is to compare the costs of disinfection practices taking into account their efficacies in lowering the probability of microbiological problems.

The impacts are measured as the difference between the likelihoods of having microbiological problems in water systems with and without the disinfection methods, controlling for other factors, and are estimated by using data from Canadian Municipal Water and Wastewater Survey (MWWS, 2006). This is a different measure than those frequently used in epidemiological studies such as household-intervention or community-intervention studies where the impacts are measured as the difference between the incidence rates of Acute Gastrointestinal Illness (AGI) before and after an intervention (see Colford et al., 2006; Calderon and Craun, 2006). In other words, while we assume a positive relationship between the likelihood of microbiological problems and the incident rates of AGI, we do not try to quantify this relationship. The costs of disinfection methods that are imputed from the annual operation and maintenance expenditures are then compared with each other taking into account the estimated impacts. The remainder of the paper is organized as follows. In section 2 , we develop the model that is used to estimate the impacts and operational and maintenance costs and to calculate the unit cost per expected volume of safe drinking water. The data used 


\section{KHALEGHI, DORE Water Disinfection Policies}

is explained in section 3. The results and discussions are presented in section 4 and conclusion is drawn in section 5 .

\section{Model}

A recursive, simultaneous bivariate probit model is used to estimate the marginal effects (impacts) for different disinfection methods. The model accounts for simultaneity between the probability of having microbiological problems and the choice of disinfection method in a drinking water system. In other words, the same factors that determine the likelihood of having microbiological problems may also influence the choice of disinfection method. For example, no disinfectant may be used when water is withdrawn from high quality source water. In this case, the low rate of microbiological problems is rather due to the high quality of source water than the lack of any disinfectants.

Suppose that in a drinking water system $i$, the difference between the contamination levels and drinking water standards is given by the latent variable $y_{i 1}^{*}$. If the latent variable is positive, in other words if the contamination levels are greater than the drinking water standards, the drinking water system will report a microbiological quality problem, $y_{i 1}=1$; otherwise $y_{i 1}=0$. The decision to use the minimum required disinfection method depends on the quality of water which itself depends on the characteristics of source water and water system. Suppose that the latent variable $y_{i 2}^{*}$ represents the quality of water in the drinking water system $i$. If water is withdrawn from high quality source water (e.g., with well protected watershed, low turbidity and historically low microbiological problems), the minimum required disinfection method will be used $y_{i 2}=1$; otherwise $y_{i 2}=0$. The recursive, simultaneous bivariate probit model is written as:

$y_{i 1}^{*}=x_{i 1} \beta_{1}+\gamma y_{i 2}+\varepsilon_{i 1}, \quad y_{i 1}=1$ if $y_{i 1}^{*}>0,0$ otherwise.

$y_{i 2}^{*}=x_{i 2} \beta_{2}+\varepsilon_{i 2}, \quad y_{i 2}=1$ if $y_{i 2}^{*}$ is from high quality source water, 0 otherwise.

where $x_{i j}(j=1,2)$ are matrices of explanatory variables and $\varepsilon_{i j}(j=1,2)$ represent the error terms that are assumed to have independent, identical bivariate normal distribution. ${ }^{2}$

The drinking water system reports a microbiological quality problem if the contamination levels are greater than the drinking water standards (i.e., $y_{i 1}^{*}>0$ ). The conditional mean of experiencing microbiological problems (i.e., $y_{i 1}=1$ ) is given by:

\footnotetext{
2 Maddala (1983) shows that while the dependent variable $y_{i 2}$ appears as one of the explanatory variables in the first equation, the endogenous nature of the recursive, simultaneous equations can be ignored in the maximization of the log-likelihood.
} 
Review of Economic Analysis 4 (2012) 209-223

$$
\begin{aligned}
E\left(y_{1} \mid x_{1}, x_{2}\right) & =\operatorname{Prob}\left(y_{2}=1\right) E\left(y_{1} \mid y_{2}=1, x_{1}, x_{2}\right)+\operatorname{Prob}\left(y_{2}=0\right) E\left(y_{1} \mid y_{2}=0, x_{1}, x_{2}\right) \\
& =\Phi_{2}\left(x_{1}{ }^{t} \beta_{1}+\gamma y_{2}, x_{2}{ }^{t} \beta_{2}, \rho\right)+\Phi_{2}\left(x_{1}{ }^{t} \beta_{1},-x_{2}{ }^{t} \beta_{2},-\rho\right)
\end{aligned}
$$

where $\Phi_{2}$ is the standard normal bivariate cumulative distribution function. The marginal effect or the impact of intervention $d$ is calculated as:

$$
\text { Marginal Effect }=E\left(y_{1} \mid \bar{x}, d=1\right)-E\left(y_{1} \mid \bar{x}, d=0\right)
$$

where $\bar{x}$ represents the average value of all other variables. The risk reduction per volume of treated water per day is defined as the product of the marginal effect and the volume of treated water per day.

Further suppose that the treatment of raw water using the disinfection method $d$ requires two types of inputs namely fixed capital inputs $\left(\bar{k}_{d}\right)$ and variable operating inputs $\left(l_{d}\right)$ where the subscript $d$ represents the disinfection method. Fixed capital inputs include all types of capital goods such as equipment, structures and land. Variable operating inputs include all types of operating goods and services such as raw materials, water, energy, and labor. The production of treated water is given by:

$$
v_{d}=f_{d}\left(\bar{k}_{d}, l_{d}\right)
$$

where $f_{d}$ represents the production function for treating $v_{d}$ units of water for all combinations of inputs using the disinfection method $d$. The production function is assumed to be monotonically increasing in its inputs and hence, the variable factor, $l_{d}$, can be represented by the inverse function as:

$$
l_{d}=f_{d}^{-1}\left(\bar{k}_{d}, v_{d}\right)
$$

In the short-run, the objective of municipalities is to minimize the cost of treating $v_{d}$ units of water. Assuming that both capital and operating inputs are purchased in competitive markets with the prices $r$ and $w$, respectively, the objective of municipalities can be written as:

$$
\begin{gathered}
\text { Cost }=\min _{l_{d}} r \bar{k}_{d}+w l_{d} \\
\text { s.t } \quad v_{d}=f_{d}\left(\bar{k}_{d}, l_{d}\right)
\end{gathered}
$$

By replacing for $l_{d}$ with equation (5), the cost function can be written as:

$$
\operatorname{Cost}\left(v_{d}\right)=r \bar{k}_{d}+w f_{d}^{-1}\left(\bar{k}_{d}, v_{d}\right)
$$




\section{KHALEGHI, DORE Water Disinfection Policies}

The first term in the cost function (i.e., $r \bar{k}_{d}$ ) is invariant to the volume of treated water. It represents the cost of fixed inputs such as equipment and physical structures for the disinfection method $d$. The second term (i.e., $w f_{d}^{-1}\left(\bar{k}_{d}, v_{d}\right)$ ), however, varies with the volume of treated water. It represents the cost of variable inputs such as energy, water, raw material and labor to produce $v_{d}$ units of treated water using the disinfection method $d$. By subtracting the cost of fixed inputs from both side of equation (7), the operating cost can be written as:

$$
\text { Operating } \operatorname{Cost}\left(v_{d}\right)=\operatorname{Cost}\left(v_{d}\right)-r \bar{k}_{d}=w f_{d}^{-1}\left(\bar{k}_{d}, v_{d}\right)
$$

The operating cost function (i.e., equation 8) and the risk reduction per volume of treated water (i.e., equation 3) are used to compare different disinfection methods based on their unit cost per expected volume of safe drinking water:

$$
\text { Unit cost per expected volume of safe drinking water }=\frac{\text { Operating } \operatorname{Cost}\left(v_{d}\right)}{\left(1-E\left(y_{1} \mid \bar{x}, d=1\right)\right) v_{d}}
$$

\section{Data}

Data about the disinfection methods are retrieved from Canadian Municipal Water and Wastewater Survey (MWWS, 2006). ${ }^{3}$ According to Environment Canada (2006), "the MWWS is a Canada-wide (excluding Federal lands) survey of public-serving community drinking water and/or wastewater utilities serving at least 100 residents or 50 total connections." Territories are excluded due to their limited number of observations (e.g., only one of the two listed jurisdictions in Yukon was surveyed in 2006 and from the six listed jurisdictions in Nunavut and Northwest Territories, zero and one were surveyed, respectively). Data had to be aggregated to the municipal level to merge different data sets (i.e., tables or raw survey data from MWWS). This makes the census subdivision, defined by Statistic Canada, the unit of measurement.

The survey reveals that aquifers (36.6\%), rivers (27.3\%) and lakes (26\%) are the most common sources of raw water in municipalities. Surface water accounts for $88 \%$ of the treated water by volumes (Statistics Canada, 2009). The data contains 36 (8.13\%) jurisdictions with both quality and quantity problems; 87 (19.64\%) and 44 (9.93\%) jurisdictions with either quality or quantity problems, respectively and 276 (62.3\%) jurisdictions with no problem in their drinking water systems in 2006. Table 1 shows the number of jurisdictions with reported quality and/or quantity problems in their drinking water systems by province. In absolute terms, Quebec with 21 quality and 15 joint quality and

\footnotetext{
${ }^{3}$ Data is accessible at http://www.ec.gc.ca/water/mwws/en/index.cfm.
} 
quantity problems has the highest number of quality problems in its drinking water systems followed by Ontario with 14 quality and 8 joint quality and quantity problems, and British Columbia with 15 quality and 4 joint quality and quantity problems. However, in relative terms, Newfoundland and Labrador ranks first with 35\% of its surveyed jurisdictions reporting a quality problem followed by British Columbia (34.55\%) and Nova Scotia (33.33\%) while Quebec (31.58\%) and Ontario (23.66\%) rank fourth and eighth, respectively.

Table 1: Number of Jurisdictions with Quality and/or Quantity Problems by Province

\begin{tabular}{|c|c|c|c|c|c|c|}
\hline & \multirow[b]{2}{*}{$\begin{array}{c}\text { All } \\
\text { Jurisd. }\end{array}$} & \multirow[b]{2}{*}{$\begin{array}{l}\text { Surveyed } \\
\text { Jurisdictions }\end{array}$} & \multicolumn{4}{|c|}{ Surveyed Jurisdictions } \\
\hline & & & $\begin{array}{c}\text { Quality } \\
\text { Problem }\end{array}$ & $\begin{array}{l}\text { Quantity } \\
\text { Problem }\end{array}$ & $\begin{array}{c}\text { Both } \\
\text { Problems }\end{array}$ & $\begin{array}{c}\text { No } \\
\text { Problem }\end{array}$ \\
\hline $\mathrm{AB}$ & 159 & 67 (42.14\%) & $14(20.90 \%)$ & 12 (17.91\%) & $3(4.48 \%)$ & 38 (56.72\%) \\
\hline BC & 123 & 55 (44.72\%) & 15 (27.27\%) & 7 (12.73\%) & $4(7.27 \%)$ & 29 (52.73\%) \\
\hline MB & 89 & 29 (32.58\%) & 3 (10.34\%) & $1(3.45 \%)$ & $1(3.45 \%)$ & 24 (82.76\%) \\
\hline NB & 55 & 21 (38.18\%) & 5 (23.81\%) & $2(9.52 \%)$ & $1(4.76 \%)$ & 13 (61.90\%) \\
\hline NL & 48 & 20 (41.67\%) & 5 (25.00\%) & $1(5.00 \%)$ & 2 (10.00\%) & 12 (60.00\%) \\
\hline NS & 30 & $9(30.00 \%)$ & 2 (22.22\%) & $0(0.00 \%)$ & $1(11.11 \%)$ & $6(66.67 \%)$ \\
\hline ON & 227 & 93 (40.97\%) & 14 (15.05\%) & $7(7.53 \%)$ & $8(8.60 \%)$ & 64 (68.82\%) \\
\hline PEI & 11 & 5 (45.45\%) & $1(20.00 \%)$ & $0(0.00 \%)$ & $0(0.00 \%)$ & 4 (80.00\%) \\
\hline QC & 406 & 114 (28.08\%) & 21 (18.42\%) & 14 (12.28\%) & 15 (13.16\%) & 64 (56.14\%) \\
\hline SK & 86 & 30 (34.88\%) & 7 (23.33\%) & $0(0.00 \%)$ & $1(3.33 \%)$ & 22 (73.33\%) \\
\hline Total & 1234 & 443 (35.90\%) & 87 (19.64\%) & 44 ( 9.93\%) & 36 ( 8.13\%) & 276 (62.30\%) \\
\hline
\end{tabular}

Table 2 reports number of jurisdictions by the reported disinfection methods at their water treatment facilities by province. As can be seen from Table 2, free chlorine is the most commonly used disinfectant in the water treatment facilities. In $71.9 \%$ of the treatment facilities, free chlorine is the primary disinfectant and is used as the secondary disinfectant in $24.2 \%$ of the treatment facilities. Less than $4 \%$ of the surveyed jurisdictions have no reported disinfectant at their treatment facilities. UV (11.3\%) and ozone (6.5\%) are the next two most used disinfection methods in the treatment facilities. 
KHALEGHI, DORE Water Disinfection Policies

Table 2: Number of Jurisdictions by the Reported Disinfection Methods at Their Water Treatment Facilities by Province

\begin{tabular}{|c|r|r|r|r|r|r|c|}
\hline & $\begin{array}{c}\text { Free } \\
\text { chlorine }\end{array}$ & Chloramines & $\begin{array}{c}\text { Chlorine } \\
\text { dioxide }\end{array}$ & UV & Ozone & None & All \\
\hline AB & $58(81.7 \%)$ & $5(7.0 \%)$ & $1(1.4 \%)$ & $6(8.5 \%)$ & $0(0.0 \%)$ & $1(1.4 \%)$ & 71 \\
BC & $27(73.0 \%)$ & $0(0.0 \%)$ & $0(0.0 \%)$ & $4(10.8 \%)$ & $0(0.0 \%)$ & $6(16.2 \%)$ & 37 \\
MB & $27(75.0 \%)$ & $1(2.8 \%)$ & $1(2.8 \%)$ & $3(8.3 \%)$ & $4(11.1 \%)$ & $0(0.0 \%)$ & 36 \\
NB & $13(81.3 \%)$ & $0(0.0 \%)$ & $0(0.0 \%)$ & $1(6.3 \%)$ & $0(0.0 \%)$ & $2(12.5 \%)$ & 16 \\
NL & $13(92.9 \%)$ & $0(0.0 \%)$ & $0(0.0 \%)$ & $0(0.0 \%)$ & $0(0.0 \%)$ & $1(7.1 \%)$ & 14 \\
NS & $12(92.3 \%)$ & $0(0.0 \%)$ & $0(0.0 \%)$ & $1(7.7 \%)$ & $0(0.0 \%)$ & $0(0.0 \%)$ & 13 \\
ON & $70(64.2 \%)$ & $8(7.3 \%)$ & $1(0.9 \%)$ & $28(25.7 \%)$ & $2(1.8 \%)$ & $0(0.0 \%)$ & 109 \\
PEI & $1(33.3 \%)$ & $0(0.0 \%)$ & $0(0.0 \%)$ & $2(66.7 \%)$ & $0(0.0 \%)$ & $0(0.0 \%)$ & 3 \\
QC & $60(61.2 \%)$ & $2(2.0 \%)$ & $7(7.1 \%)$ & $1(1.0 \%)$ & $21(21.4 \%)$ & $7(7.1 \%)$ & 98 \\
SK & $31(83.8 \%)$ & $1(2.7 \%)$ & $1(2.7 \%)$ & $3(8.1 \%)$ & $1(2.7 \%)$ & $0(0.0 \%)$ & 37 \\
\hline All & $312(71.9 \%)$ & $17(3.9 \%)$ & $11(2.5 \%)$ & $49(11.3 \%)$ & $28(6.5 \%)$ & $17(3.9 \%)$ & 434 \\
\hline
\end{tabular}

\section{Results}

It is important to address some issues before turning to the results. The first issue is that some variables had to be grouped due to their limited variations among jurisdictions. For example, by law, water entering the distribution system is required to have a specific amount of chlorine residual. This implies little variation with regard to the use of free chlorine among jurisdictions. As a result, disinfection methods are grouped into six groups based on the use of primary disinfection method as (1) no disinfectant is reported, (2) free chlorine, (3) chloramines, (4) chlorine dioxide, (5) UV, and (6) ozone.

The next issue is whether the microbiological water quality problem, as defined in the survey, is a good proxy for measuring the effectiveness of disinfection methods in lowering the probability of microbiological problems. In other words, while one can postulate a lower probability of microbiological problems associated with the use of a specific method, the recorded microbiological problems may include failures of equipment or some other unobserved factors and hence, it may be a poor indicator of the effectiveness of disinfection methods. The concern about how well a true unobserved microbiological problem is characterized by a variable is not unique to this study (for example, see Messner et al., 2006). Nonetheless, it is assumed that the probability of microbiological problems is highly correlated with the reported microbiological quality problems and hence, the distinction is negligible. The other issue is that the mere use of a disinfectant does not imply its effective use. For example, while the use of chloramines provides a longer residual effect, it requires a careful monitoring of the ratio of added chlorine to ammonia of 5 to 1 . At any ratio above this 
the chlorine residual in the system substantially decreases. Therefore the use of chloramines does not necessarily imply its effective use. The last issue is that data on the use of disinfection methods are available in three levels in MWWS (2006). These are water source, treatment plant and distribution system. As a result, a disinfection method for a water system can be imputed based on each one of these data sets. While the discussion of the results in what follows is based on the aggregate model, the results from applying the model to each one of these data sets are also reported.

Table 3: Estimates of the Recursive Bivariate Probit Model

\begin{tabular}{|c|c|c|c|c|}
\hline \multicolumn{5}{|c|}{ First Eq: Quality Problem } \\
\hline Variable & Source Water & Treatment Plant & $\begin{array}{l}\text { Distribution } \\
\text { System }\end{array}$ & Aggregate \\
\hline Constant & 0.107 & $-0.683^{* * *}$ & $-0.662 * * *$ & $-0.470 *$ \\
\hline Groundwater & -0.159 & -0.136 & $-0.140 *$ & $-0.245^{* *}$ \\
\hline Free Chlorine & $-1.039 * * *$ & - & -0.101 & - \\
\hline Chloramines & $-0.883^{* * *}$ & 0.418 & -0.286 & -0.475 \\
\hline Chlorine dioxide & -0.093 & -0.066 & 0.221 & $-0.442 * *$ \\
\hline UV & $-1.398^{* * *}$ & -0.228 & -0.177 & $-0.680^{* *}$ \\
\hline Ozone & $-0.604 *$ & $-0.345^{* * *}$ & -0.667 & $-0.864^{* * *}$ \\
\hline Filtration & - & -0.119 & - & -0.143 \\
\hline $\begin{array}{l}\text { Population } \\
(000,000)\end{array}$ & $1.122^{* * *}$ & $0.908^{* * *}$ & $0.960^{* * *}$ & $0.941^{* * *}$ \\
\hline \multicolumn{5}{|c|}{ Second Eq: } \\
\hline Use of disinfectant & None & Free Chlorine & None & Free Chlorine \\
\hline Groundwater & 0.261000 & $0.687000^{* * *}$ & 0.425000 & $0.576000^{* * *}$ \\
\hline Mains $(\mathrm{km})$ & $-0.000414^{* *}$ & 0.000021 & -0.000025 & $-0.000038^{*}$ \\
\hline Constant & $-0.887000^{* * *}$ & $0.523000^{* * *}$ & $-0.973000 * * *$ & $0.513000^{* * *}$ \\
\hline Rho & $-0.463000 * * *$ & 0.000000 & 0.000000 & $-0.331000 * *$ \\
\hline$N$ & 407 & 360 & 495 & 360 \\
\hline Log likelihood & -410.38 & -378.34 & -502.22 & -388.31 \\
\hline Wald chi2 & 34.53 & 25.96 & 25.14 & 25.82 \\
\hline LR-Rho chi2 & 4.7130 & 0.7370 & 1.0230 & 2.8510 \\
\hline Prob > chi2 & 0.0001 & 0.0021 & 0.0028 & 0.0022 \\
\hline Prob > chi2 & 0.0299 & 0.3907 & 0.3117 & 0.0913 \\
\hline
\end{tabular}

* indicates $10 \%$, ** indicates $5 \%$, *** indicates $1 \%$ significance levels. 


\section{KHALEGHI, DORE Water Disinfection Policies}

Table 3 shows the results from the recursive, simultaneous bivariate probit model. The base cases in the first and third models are surface water or groundwater under the direct influence of surface water without using any disinfectants (these models use data from source water and water distribution system, respectively) and the base cases in the second and fourth models are surface water or groundwater under the direct influence of surface water with the use of free chlorine as the only disinfectant (these models use data from water treatment facilities and the aggregated data, respectively). The use of different base cases is due to the fact that there are only a few water treatment facilities in the survey that have no reported water disinfection methods. In each model, the first equation represents the equation for water quality problem and the second equation represents the simultaneous equation for the choice of disinfectant. The likelihood ratio test rejects the absence of correlation between the two equations in the model. This result, as expected, indicates that the quality of source water influences both the probability of having a microbiological quality problem and the choice of disinfection method.

Table 4 presents the marginal effects by using the estimated results from the above aggregate model. As can be seen from Table 4, water systems that withdraw water from groundwater sources are on average 6.94\% (95\% CI, $-12.76 \%-1.12 \%)$ less likely to experience a quality problem compared with the systems that withdraw water from surface water or groundwater under the direct influence of surface water. While the estimated coefficient for the use of chloramines indicates a lower probability of experiencing a microbiological quality problem, this result is statistically insignificant which implies that on average the use of chloramines is not more effective than the use of free chlorine. This can be due to a number of factors such as the high sensitivity of residual chlorine to the ratio of added chlorine to ammonia or that provision of suitable disinfectant Contact Times (CTs) is more problematic for the use of chloramines since it requires longer CTs.

Table 4: Estimates of the Marginal Effects (Aggregate Model)

\begin{tabular}{|l|r|r|r|r|}
\hline Variable & Marginal Effect & p-value & \multicolumn{2}{|c|}{$95 \%$ CI } \\
\hline First Eq: Quality Problem & & & & \\
Groundwater & -0.0694282 & 0.019 & -0.127679 & -0.011177 \\
Chloramines & -0.1191005 & 0.226 & -0.312090 & 0.073889 \\
Chlorine dioxide & -0.1030188 & 0.028 & -0.194689 & -0.011348 \\
UV & -0.1582522 & 0.017 & -0.288437 & -0.028067 \\
Ozone & -0.1815824 & 0.000 & -0.239704 & -0.123461 \\
Filtration & -0.0419240 & 0.319 & -0.124301 & 0.040453 \\
Pop (000,000) & 0.2824417 & 0.000 & 0.171297 & 0.393587 \\
\hline
\end{tabular}


On average, jurisdictions that use chlorine dioxide are 10.3\% (95\% CI, -19.46\% -1.13\%) less likely to experience a quality problem. Both UV and ozone are effective disinfectants against harmful pathogens; however, neither of them leaves residual disinfectant in the distribution system. Therefore, they are often used with a chlorine-based disinfectant to compensate for the lack of residual disinfectant in the distribution system. On average, the probability of having a quality problem is $15.82 \%$ (95\% CI, $-28.83 \%-2.8 \%)$ and $18.15 \%$ (95\% CI, -23.97 12.35) lower when UV or ozone is used as the primary water disinfection methods, respectively. While the coefficient of filtration indicates a lower probability of having a microbiological quality problem, this result is statistically insignificant. Finally, populous areas are more likely to experience a microbiological quality problem in their drinking water systems. This can be due to a higher cross contamination in more populous jurisdictions.

In the empirical application of the model, the operational cost of treating $v_{d}$ units of water per day (equation 8) is modeled as a Cobb-Douglas cost function:

$$
\text { Operating Cost }\left.\left(v_{d}\right)\right|_{d}=\alpha_{d} v^{\beta_{d}} e^{u}
$$

where $\alpha_{d}$ and $\beta_{d}$ are the parameters of the model and $u$ is a vector of random disturbances. The model assumes that, everything else being equal, on average plants with the same volume of processed water have the same proportion of labor, administration, maintenance, raw material and energy costs and therefore, any differences in their annual costs can be attributed to their adopted disinfection methods. The parameters of the model are estimated by transforming the model to a log-linear model and using the expenditures and volumes of treated water data from MWWS $(2004,2006) .{ }^{4}$ Regional dummy variables are included to control for variation in energy prices and labor costs across regions. These variables are British Columbia, Prairies (Alberta, Manitoba, and Saskatchewan), Central Canada (Ontario, Quebec), and Atlantic Canada (New Brunswick, Nova Scotia, Newfoundland and Labrador, and Prince Edward Island).

Table 5 presents the estimates of the cost functions. While the estimates of $\alpha_{d}$ 's indicate that the use of chloramines, UV and ozone require more expensive equipment compared with the use of free chlorine, the estimates of $\beta_{d}$ 's indicate lower incremental increase in costs for treating one more unit of water by using these methods. While the regional dummy variables appear to be individually insignificant, a joint significant F-test with high confidence rejects the null hypothesis that all regional dummy variables are zero.

${ }^{4}$ Expenditure includes expenditures spent on regular labor, treatment supplies, maintenance, replacement and purchase of bulk water. 
KHALEGHI, DORE Water Disinfection Policies

Table 5: Estimates of the cost functions

\begin{tabular}{|l|l|l|l|l|l|l|}
\hline & Chlorine & Chloramines & $\begin{array}{l}\text { Chlorine } \\
\text { dioxide }\end{array}$ & \multicolumn{1}{|c|}{ UV } & Ozone & Aggregate \\
\hline$\alpha_{\text {other/none }}$ & $2.670^{* * *}$ & $1.804^{* *}$ & $2.368^{* *}$ & $2.301^{* *}$ & 0.693 & $2.661^{* *}$ \\
$\alpha_{\text {treatment }}{ }^{+}$ & $0.557^{* *}$ & 0.758 & 1.170 & $0.846^{*}$ & 0.927 & $0.510^{* *}$ \\
$\alpha_{\text {chlorine }}$ & $2.091^{*}$ & & & & & $2.086^{*}$ \\
$\alpha_{\text {chloramines }}$ & & 4.930 & & & & $4.864^{* *}$ \\
$\alpha_{\text {UV }}$ & & & 1.816 & & & $2.222^{* *}$ \\
$\alpha_{\text {Ozone }}$ & & & & $4.660^{* * *}$ & & $3.954^{* * *}$ \\
\hline$\beta_{\text {other/none }}$ & $0.711^{* * *}$ & $0.743^{* * *}$ & $0.788^{* * *}$ & $0.775^{* * *}$ & $0.735^{* * *}$ & $0.708^{* * *}$ \\
$\beta_{\text {chlorine }}$ & $-0.261^{* *}$ & & & & & $-0.259^{* *}$ \\
$\beta_{\text {chloramines }}$ & & -0.478 & & & & $-0.463^{*}$ \\
$\beta_{\text {chlorine dioxide }}$ & & & -0.238 & & & -0.230 \\
$\beta_{\text {UV }}$ & & & & $-0.536^{* *}$ & & $-0.404^{* *}$ \\
$\beta_{\text {Ozone }}$ & & & & & $-0.513^{* * *}$ & $-0.494^{* * *}$ \\
\hline British & & & -1.542 & -1.002 & 1.309 & 0.083 \\
Columbia & & & -0.262 & -0.059 & 1.835 & -0.485 \\
Prairies & $-0.526^{* * *}$ & 0.220 & -0.826 & -0.782 & 1.153 & -0.403 \\
Central & -0.428 & 0.259 & -0.636 & & & -0.795 \\
Atlantic & $-0.822^{* *}$ & 0.190 & 0.567 & 0.450 & 0.491 & 0.377 \\
\hline$R^{2}$ & 0.348 & 0.489 & 5.90 & 6.92 & 8.06 & 11.48 \\
$F(k-1, N-k)$ & 15.83 & 11.11 & 45 & 78 & 57 & 320 \\
$N$ & 233 & 59 & & & & \\
\hline
\end{tabular}

Both White (1980) and Breusch-Pagan (1979) tests reject the assumption of constant variances; hence White's heteroscedasticity consistent standard errors are used. In addition, standard errors are adjusted for regional clusters.

${ }^{+}$If any of coagulation, flocculation, sedimentation, slow-sand, micro-straining, granular, membrane filtration is used. * indicates $10 \%$, ** indicates $5 \%$, *** indicates $1 \%$ significance levels.

Figure 1 depicts the unit cost per expected volume of safe drinking water, equation (9), using the estimated parameters from the above aggregate model. It shows that the unit cost of using free chlorine at low volumes of treated water after accounting for the risk reduction per volume of treated water is still lower than the other disinfection methods. This is because other disinfection methods require expensive equipment, maintenance and operational costs compared with the use of free chlorine. In addition, by law the treated water entering the distribution system is required to have a specific amount of chlorine residual; hence, the use of UV or ozone needs to be supplemented with free chlorine. This result, however, does not 
factor in the potential risk caused by formation of chlorination Disinfection Byproducts (DBPs) associated with the use of chlorine-based disinfectants. In addition, due to economies of scale, the unit costs decline with the increase in the volume of treated water. The estimated results show that the unit cost per expected volume of safe drinking water for the use of UV and ozone will cross the unit cost for the use of free chlorine.

Figure 1: The cost per cubic meter of treated water

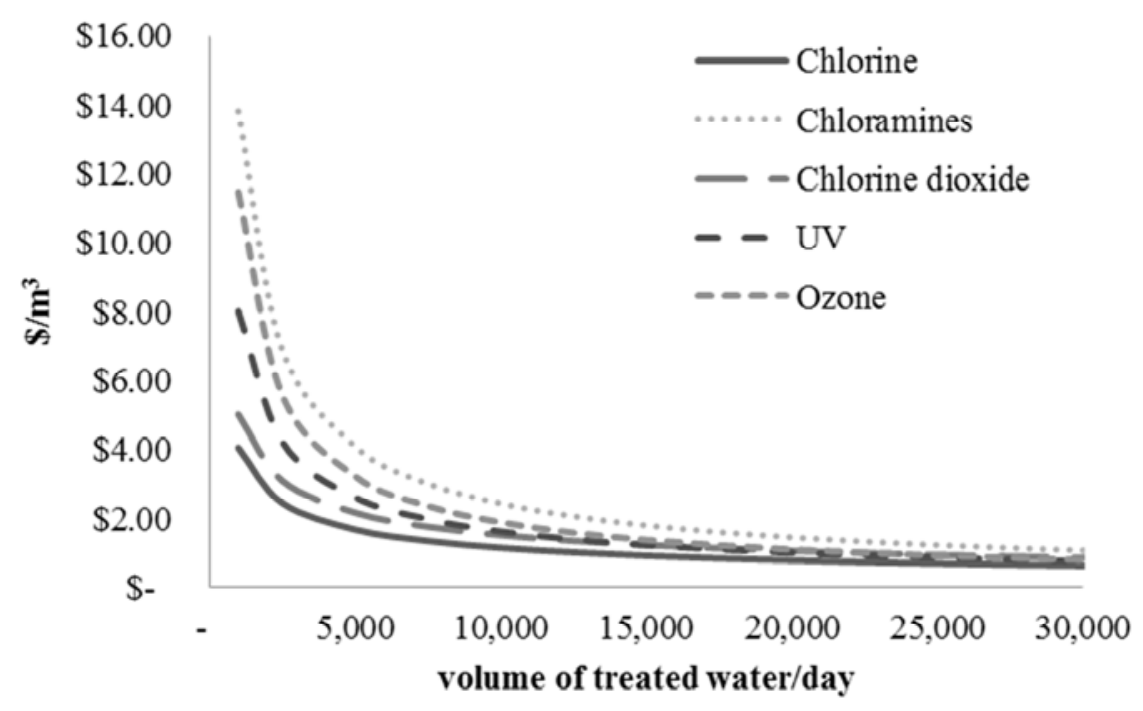

The results suggest that the use of chlorine dioxide, UV and ozone can lead to a lower likelihood of having microbiological problems in a drinking water system. Moreover, while the use of free chlorine has a lower unit cost per cubic meter of treated water at low volumes of treated water, this advantage dissipates with the increase in the volume of treated water due to economies of scale. ${ }^{5}$ These results suggest that the dominant use of chlorine-based disinfectant in medium to large size drinking water systems in Canada cannot be based on cost comparisons alone and other time-dependent factors might be in place. One explanation is that historically electricity was not readily available in many areas and hence, the use of free chlorine was the only option available at the time, but that continues to be the dominant practice up to this day. The policy implication of the results is that Canadian municipalities

5 Canada has one of the highest water intakes per capita among the Organization for Economic Cooperation and Development (OECD) countries. Boyd (2001) reported average water intakes of 4,383 liters per capita per day in Canada in 1999 which is only second to the US with average water intakes of 4,931 liters per capita per day in the same year. Canada also ranks second in terms of total average daily flow of municipal water per person (i.e., 555 liters per capita per day in 2006) and average daily residential flow of water per person (i.e., 329 liters per capita per day in 2006). 


\section{KHALEGHI, DORE Water Disinfection Policies}

should give UV and/or ozone technologies serious consideration when modernizing their treatment facilities. Canadian municipal water treatment plants will require considerable renovation and transformation in coming years.

The required capital investment to meet water and wastewater infrastructure needs in Canada is estimated to have a deficit of between $\$ 38$ to $\$ 90$ billion for the 20-year period (National Round Table on the Environment and the Economy, 1996; The Canadian Water Network, 2005; Mirza, 2007). ${ }^{6}$ Canadian municipal water treatment plants reported \$885 million capital expenditures to add, expand or upgrade drinking water treatment plants in 2007 (Statistics Canada, 2009). While these expenditures are not close to the estimated shortage, they are in the right direction to meet the challenges of providing safe drinking water at reasonable costs in the future.

\section{Conclusion}

This study investigates the cost and efficacy of water disinfection practices using data from Canadian Municipal Water and Wastewater Survey (2006). The data reveals that free chlorine is the most commonly used disinfectant in the surveyed jurisdictions. It is used as a primary disinfectant in $71.9 \%$ of the drinking water treatment facilities and as a secondary disinfectant in $22.11 \%$ of the facilities. Since Canadian municipal water treatment plants will require considerable renovation and transformation in coming years (National Round Table on the Environment and the Economy, 1996; The Canadian Water Network, 2005; Mirza, 2007), it is important to investigate whether the dominant use of chlorine-based disinfectants is due to their efficacy in preventing microbiological problems or because the use of other practices such as UV or ozone imposes an unacceptably high financial burden on municipalities. Therefore, the objectives of this study are to quantify by how much (and if) the use of a disinfection practice can lower the probability of having microbiological problems in a drinking water system, and to compare the costs of disinfection practices taking into account their efficacies in lowering the probability of microbiological problems.

The results show that water systems that withdraw water from groundwater sources are on average $6.94 \%$ (95\% CI, $-12.76 \%-1.12 \%$ ) less likely to experience a microbiological quality problem compared with those that withdraw water from surface or groundwater under the direct influence of surface water. While the model predicts a lower probability of having a microbiological quality problem for the use of chloramines and for filtration, the results are statistically insignificant. On average, water systems that use chlorine dioxide are $10.3 \%$

6 The US EPA drinking water infrastructure needs survey estimated the total nationwide infrastructure need of $\$ 334$ billion in the United States for the 20-year period. Treatment systems represent $\$ 75$ billion of the total national need (United States Environmental Protection Agency 2011). 
(95\% CI, $-19.46 \%-1.13 \%$ ) less likely to experience a microbiological quality problem. The probability of having a microbiological quality problem is $15.82 \%$ (95\% CI, $-28.83 \%-2.8 \%$ ) and $18.15 \%$ (95\% CI, $-23.97-12.35$ ) lower when UV and ozone are used, respectively. Furthermore, the quality of source water appears to influence both the probability of having microbiological problems and the choice of disinfection practice.

Finally, while the use of free chlorine at low volumes of treated water appears to have a lower unit cost even after accounting for the risk reduction per volume of treated water, this advantage does not factor in the potential risk caused by formation of chlorination disinfection by-products (DBPs) associated with the use of chlorine-based disinfectants. In addition, this advantage dissipates with the increase in the volume of treated water due to economies of scale.

The results suggest that the dominant use of chlorine-based disinfectant in medium to large size drinking water systems in Canada cannot be based on cost comparisons alone and other time-dependent factors might be in place. One explanation is that historically electricity was not readily available in many areas and hence, the use of free chlorine was the only option available at the time, but that continues to be the dominant practice up to this day. Canadian municipal water treatment plants will require considerable investment to renovate and transform existing facilities in coming years. The policy implication of the results is that Canadian municipalities should give UV and/or ozone technologies serious consideration when they modernize their treatment facilities.

\section{References}

Boyd, David R. (2001), Canada vs. the OECD: An Environmental Comparison. Victoria, BC, Canada: National Library of Canada Cataloguing in Publication Data, http://www.environmentalindicators.com/htdocs/PDF/CanadavsOECD.pdf

Breusch, T. S. and A. R. Pagan (1979), Simple Test for Heteroscedasticity and Random Coefficient Variation, Econometrica, 47(5), 1287-1294.

Calderon, R. L. and G. F. Craun (2006), Estimates of Endemic Waterborne Risks from Community-intervention Studies, Journal of Water and Health, 4, 89-99.

Chevrier, C., B. Junod and S. Cordier (2004), Does Ozonation of Drinking Water Reduce the Risk of Bladder Cancer? Epidemiology, 150(6), 552-560.

Colford, J. M., S. Roy, M. J. Beach, A. Hightower, S. E. Shaw and T. J. Wade (2006), A Review of Household Drinking Water Intervention Trials and an Approach to the Estimation of Endemic Waterborne Gastroenteritis in the United States, Journal of Water and Health, 4, 71-88.

Environment Canada (2006), Municipal Water and Wastewater Survey, http://www.ec.gc.ca/water/mwws/en/index.cfm. 
KHALEGHI, DORE Water Disinfection Policies

Gagnon, Mychele, Valerie Gaudreault and Donald Overton (2008), Age of Public Infrastructure: A Provincial Perspective, Ottawa, Ontario, Canada, http://www.statcan.gc.ca/pub/11-621-m/11-621-m2008067-eng.pdf

Kasim, Khaled, Patrick Levallois, Kenneth C. Johnson and Belkacem Abdous (2006), Chlorination Disinfection by-products in Drinking Water and the Risk of Adult Leukemia in Canada, American Journal of Epidemiology, 163(2), 116-26.

King, W. D., L. D. Marrett and C.G. Wollcott (2000), Case-control Study of Colon and Rectal Cancers and Chlorination by-products in Treated Water, Cancer Epidemiol Biomarkers Prev, 9(8), 813-818.

Maddala, G. S. (1983), Limited Dependent and Qualitative Variables in Econometrics. Cambridge: Cambridge University Press.

Messner, M., S. Shaw, S. Regli, K. Rotert, V. Blank and J. Soller (2006), An Approach for Developing a National Estimate of Waterborne Disease Due to Drinking Water and a National Estimate Model Application, Journal of Water and Health, 4, 201-240.

Mirza, Saeed (2007), Danger Ahead: The Coming Collapse of Canada's Municipal Infrastructure, Federation of Canadian Municipalities, http://www.fcm.ca/Documents/ reports/Danger_Ahead_The_coming_collapse_of_Canadas_municipal_infrastructure_EN.pdf National Round Table on the Environment and the Economy (1996), State of the Debate:

Water and Wastewater Services in Canada. Ottawa, Ontario, Canada: Canadian Cataloguing in Publication Data, http://publications.gc.ca/collections/collection_2010/

trnee-nrtee/En133-27-1996-eng.pdf

Statistics Canada (2009), Survey of Drinking Water Plants 2005-2007, Research and Development - Environment Accounts and Statistics Division, http://publications.gc.ca/collections/collection_2009/statcan/16-403-X/16-403-x2009001eng.pdf

The Canadian Water Network (2005), Bringing Water Research to Life: 2004-05 Annual

Report, Canadian Water Network, http://www.cwn-rce.ca/wp-content/annualreports/CWN_Annual_Report_2004-05-en.pdf

United States Environmental Protection Agency (2011), Drinking Water Infrastructure Needs Survey and Assessment: Fourth Report to Congress, Washington, D.C.: U.S. Environmental Protection Agency, http://water.epa.gov/infrastructure/drinkingwater/ dwns/upload/2009_03_26_needssurvey_2007_report_needssurvey_2007.pdf

Villanueva, C. M., F. Fernandez, N. Malats, J. O. Grimalt and M. Kogevinas (2003), Metaanalysis of Studies on Individual Consumption of Chlorinated Drinking Water and Bladder Cancer, Journal of Epidemiol Community Health, 57(3), 166-173.

White, H. (1980), A Heteroskedasticity-consistent Covariance Matrix Estimator and a Direct Test for Heteroskedasticity, Econometrica, 48(4), 817-838. 